\title{
Genome-wide association mapping of quantitative traits in a breeding population of sugarcane
}

\author{
Josefina Racedo ${ }^{1}$, Lucía Gutiérrez $^{2,3}$, María Francisca Perera ${ }^{1 \dagger}$, Santiago Ostengo ${ }^{1 \dagger}$, Esteban Mariano Pardo ${ }^{1}$,
} María Inés Cuenya ${ }^{1}$, Bjorn Welin ${ }^{1}$ and Atilio Pedro Castagnaro ${ }^{*}$

\begin{abstract}
Background: Molecular markers associated with relevant agronomic traits could significantly reduce the time and cost involved in developing new sugarcane varieties. Previous sugarcane genome-wide association analyses (GWAS) have found few molecular markers associated with relevant traits at plant-cane stage. The aim of this study was to establish an appropriate GWAS to find molecular markers associated with yield related traits consistent across harvesting seasons in a breeding population. Sugarcane clones were genotyped with DArT (Diversity Array Technology) and TRAP (Target Region Amplified Polymorphism) markers, and evaluated for cane yield (CY) and sugar content (SC) at two locations during three successive crop cycles. GWAS mapping was applied within a novel mixed-model framework accounting for population structure with Principal Component Analysis scores as random component.
\end{abstract}

Results: A total of 43 markers significantly associated with CY in plant-cane, 42 in first ratoon, and 41 in second ratoon were detected. Out of these markers, 20 were associated with CY in 2 years. Additionally, 38 significant associations for SC were detected in plant-cane, 34 in first ratoon, and 47 in second ratoon. For SC, one marker-trait association was found significant for the 3 years of the study, while twelve markers presented association for 2 years. In the multi-QTL model several markers with large allelic substitution effect were found. Sequences of four DArT markers showed high similitude and e-value with coding sequences of Sorghum bicolor, confirming the high gene microlinearity between sorghum and sugarcane.

Conclusions: In contrast with other sugarcane GWAS studies reported earlier, the novel methodology to analyze multi-QTLs through successive crop cycles used in the present study allowed us to find several markers associated with relevant traits. Combining existing phenotypic trial data and genotypic DArT and TRAP marker characterizations within a GWAS approach including population structure as random covariates may prove to be highly successful. Moreover, sequences of DArT marker associated with the traits of interest were aligned in chromosomal regions where sorghum QTLs has previously been reported. This approach could be a valuable tool to assist the improvement of sugarcane and better supply sugarcane demand that has been projected for the upcoming decades.

Keywords: Biomass, Linkage disequilibrium, Population structure, Quantitative trait loci (QTL), Saccharum sp, Sugar

\footnotetext{
* Correspondence: atiliocastagnaro@gmail.com

${ }^{\dagger}$ Equal contributors

'Estación Experimental Agroindustrial Obispo Colombres (EEAOC)- Consejo

Nacional de Investigaciones Científicas y Técnicas (CONICET), Instituto de

Tecnología Agroindustrial del Noroeste Argentino (ITANOA), Av. William

Cross 3150, Las Talitas T4101XAC, Tucumán, Argentina

Full list of author information is available at the end of the article
} 


\section{Background}

Sugarcane, the highest tonnage crop among cultivated plants, plays a substantial role in the global economy. Nowadays, this crop has gained great importance not only for its traditional use as food ( $80 \%$ of world's sugar is produced from sugarcane) but also for ethanol and biomass production. The production of alternative energy sources as well as the establishment of the biorefinery concept has also increased sugarcane world demand rapidly [1]. In order to supply this continuous increasing requirement, the development of new varieties with high biomass and sugar yield is essential.

The modern sugarcane cultivars are interspecific hybrids derived essentially from early crosses between Saccharum officinarum $(2 \mathrm{n}=80, \mathrm{x}=10)$, a species with high sugar content stalks, and Saccharum spontaneum $(2 \mathrm{n}=$ $40-128, x=8$ ), a wild and vigorous species resistant to several sugarcane diseases. The initial interspecific hybrids were repeatedly backcrossed to $S$. officinarum clones or to other hybrids in order to recover high sugar content, a process known as "nobilization". These modern cultivars are highly polyploid and often aneuploid, with chromosome numbers ranging from 100 to 130 [2]. Due to this genetic complexity, the application of both conventional and molecular breeding is a challenge in sugarcane.

Most of sugarcane production regions have their own breeding programs to develop and improve local varieties adapted to their specific environments and agricultural practices. Developing a new sugarcane variety takes on average 12 years [3]. Molecular markers associated with relevant agronomic traits could significantly reduce the time and cost involved in developing new varieties because they could aid in selecting the best parents as well as accelerating the rate of genetic gain in the breeding program. In that sense, association mapping has become widely used to identify molecular markers associated with relevant traits in several crops [4-9]. This method is based on the linkage disequilibrium (LD) between molecular markers and quantitative trait loci (QTL) [10]. The resolution and applicability of association mapping depends on the extent of LD within the population under consideration. The breeding history of sugarcane, consisting of a strong foundation bottleneck followed by a small number of cycles of intercrossing and vegetative propagation, suggest that LD should be extensive, thus a high density of markers may not be needed to detect marker-trait associations [11]. In 1999 [12], and more recently in 2008 [13], the persistence of high LD in modern sugarcane cultivars was confirmed.

The forces generating and/or conserving LD are those that produce allele frequency changes, i.e. population stratification, genetic relatedness, selection, mutation, genetic drift and linkage [10]. With the exception of linkage, all the genetic forces may cause false positive correlation between markers and traits in populationbased association mapping approaches. The effects of a structured population in association mapping studies have been well documented and identified as one of the main causes of spurious associations [14-16]. For that reason and considering the often complex relationships among genotypes in breeding populations, it is extremely important to control for population structure in order to effectively decrease type I error rates (i.e. false positives) [17]. For this purpose, a range of statistical methodologies have been developed that include some sort of population or relatedness control using mixed models [16-19].

In addition to controlling for population structure, the availability of both accurate phenotypic data and molecular markers distributed across the genome are critical requirements for the success of association mapping. One of the advantages of this mapping method for plants compared to classical QTL analysis based on balanced mapping populations is that association mapping allows the use of historical phenotypic data sets collected by the breeding programs [5]. Typically, this data come from multiple trials across different environments and years, therefore, statistical analysis such as mixed models are necessary to obtain phenotypic values that best represent the performance of each genotype. Malosetti et al. [19] extended the standard phenotypic analysis of multiple trials by mixed models to arrive at models suitable for association mapping by introducing marker genotype information as random covariates to model the correlation between genotypes.

The recently developed technology of DArT in sugarcane [1] makes it possible to have genome-wide scans of this genetically complex crop, capturing genomic profiles with many thousands of polymorphic markers of several kinds (INDELs, SNPs, methylation changes) [20]. Another molecular marker system recently developed that could also be convenient to detect markers associated with desirable traits is Target Region Amplification Polymorphism (TRAP). These dominant markers enable the identification of polymorphisms in coding regions involved in specific pathways as sucrose metabolism or drought tolerance among others [21, 22].

Information of the marker sequences for DArT is available and could be anchored to the sugarcane genome if sequenced. Several efforts are still ongoing in order to sequence the sugarcane genome which has a high genetic complexity due to its ploidy level. However, considering that i) sugarcane monoploid genome estimated on $930 \mathrm{Mb}$ is similar to the sorghum genome $(2 n=2 x=10)$ estimated on $730 \mathrm{Mb}$ [23]; ii) sugarcane and sorghum both belong to the Poaceae family and the same sub-tribu Saccharinae, and iii) their high degree of colinearity [24, 25]; the available sequence of sorghum genome becomes an important tool for the analysis of regions of interest in sugarcane. 
The goal of this research was to establish an appropriate genome-wide association analysis (GWAS) tool in a sugarcane breeding population, and to find molecular markers associated with high yield of both biomass and sugar stable through successive crop cycles. Therefore, a GWAS mapping within a mixed-model framework following Malosetti et al. [19] was used. Spurious associations were minimized while the power to detect true associations was maximized by considering the possible population structure. A Principal Component Analysis (PCA) from a genotype data set was performed [26] and values obtained from the significant axes for each genotype were used as covariates in the model. In contrast with others sugarcane GWAS studies reported earlier involving yield related traits $[27,28]$ where analyzes were conducted at plant-cane stage, the novel methodology to analyze multi-QTLs through successive crop cycles used in the present study allowed us to find several markers associated with relevant traits. Results highlighted that this approach could be a valuable tool to assist the improvement of sugarcane and better supply the sugar and biomass demand that has been projected for the upcoming decades.

\section{Methods}

\section{Plant material and phenotyping}

The experimental population consisted on sugarcane clones from the selection panel (Infield Variety Trials, IVT) of the sugarcane breeding program of "Estación Experimental Agroindustrial Obispo Colombres" (SCBPEEAOC) (i.e. 88 clones, Table 1). IVT are the fourth step of selection of SCBP-EEAOC, where in 2008 a total of 100 clones were planted and thoroughly evaluated in 2009 in order to select potentially new varieties at the following steps. This breeding population consists in genotypes obtained from crosses between the best parents, i.e. with highly productive offspring. To avoid the overrepresentation of any family, out of the 100 clones, 14 full-sibs were removed to assemble the panel suitable for association mapping. Only some full-sib clones were conserved for not reducing the number of genotypes of the population. The first and second more planted varieties in Tucumán (Argentina) LCP 85-384 and TUCCP 77-42, respectively [29], were also included in the association panel. The IVT were conducted at two locations in Tucumán, Argentina (Additional file 1) during three successive crop cycles. Within each trial, a randomized complete-block design with three replications was used. The individual plot size was 3 rows $\mathrm{x} 10 \mathrm{~m}$, with an inter-row spacing of $1.6 \mathrm{~m}$. Cane yield $(\mathrm{CY})\left(\mathrm{kg} \mathrm{plot}^{-1}\right)$ was evaluated directly by weighing stalks from the full plot in the field during the harvesting season 2009 (plant cane), 2010 (first ratoon), and 2011 (second ratoon). Even though CY was measured in $\mathrm{kg}$ plot $^{-1}$ in the present GWAS study, final effects were converted to $t$ $\mathrm{ha}^{-1}$ for a better interpretation. In May of each year, sugar content (SC) was estimated from ten randomly chosen stalks from each plot by determining Brix ${ }^{\circ}$ (percentage of soluble solids, mostly sugars, minerals, and organic acids) and Pol (level of sucrose in stalk juice determined by polarimetry) [30, 31]. SC was determined at the millroom of an EEAOC's laboratory by using Brix ${ }^{\circ}$ and Pol, according to the following equation:

$$
\mathrm{SC} \%=0.98 \times \text { pol } \%-0.28 \times \text { brix } \%
$$

\section{Statistical analysis for the phenotypic data}

Field trials were analyzed for each harvesting season independently using the following mixed model:

$$
\mathrm{y}_{i j k}=\mu+\mathrm{G}_{i}+\mathrm{S}_{j}+\mathrm{B}_{k(j)}+\mathrm{GS}_{(i j)}+i j k
$$

where $\mathrm{y}_{i j k}$ is yield of genotype $i$ at location $j$ and block $k ; \mu$ is the overall mean; $\mathrm{G}_{i}$ is the $i$-th genotype fixed effect with $i=1, \ldots, g ; \mathrm{S}_{j}$ is the $j$-th location random effect with $j=1, \ldots, s$ and $\mathrm{S}_{\mathrm{j}} \sim \mathrm{N}\left(0, \sigma_{\mathrm{S}}^{2}\right) ; \mathrm{B}_{k(j)}$ is the $k$-th block random effect at location $j$ with $k=1, \ldots, n$ and $\mathrm{B}_{\mathrm{k}(\mathrm{j})} \sim \mathrm{N}\left(0, \sigma_{\mathrm{B}}^{2}\right) ; \mathrm{GS}_{(i j)}$ is the genotype $i$ by location $j$ interaction random effect with $\mathrm{GS}_{(\mathrm{ij})} \sim \mathrm{N}(0$, $\left.\sigma_{\mathrm{GS}}^{2}\right)$; and $\varepsilon_{i j k}$ is the random error associated with observation $\mathrm{y}_{i j k}$. Comparison through harvesting seasons is particularly interesting since dynamics and characteristics of plant-cane bud sprouting and growth are different from those of ratoon crop [33]. Therefore, different genome regions would be implied in yield of both cane and sugar, through different crop ages. The estimated means (Best Linear Unbiased Estimator, BLUE) obtained from this model for $\mathrm{CY}$ and $\mathrm{SC}$ of all genotypes were used for the association mapping analysis. The analysis was performed using PROC MIXED in SAS software 9.0 (SAS Institute 2004). A mixed model for association mapping was used later (described below) and therefore, BLUEs instead of BLUPs were used as genetic values for the accessions to avoid double-shrinking [34-38]. Pearson correlation of genotypic means was estimated between traits in $\mathrm{R}$ software [39]. Broad-sense heritability $\left(\mathrm{H}^{2}\right)$ at an experimental level was calculated on a genotype mean basis for each trait and at each location as the ratio of genotypic to phenotypic variance, using the components of variance obtained from a model adjusted as follows:

$$
H^{2}=\frac{\sigma_{G}^{2}}{\sigma_{G}^{2}+\sigma_{\varepsilon}^{2} / r}
$$

where $\sigma_{G}^{2}$ is the genetic variance, $\sigma_{\varepsilon}^{2}$ the residual variance and $r$ the number of replicates [40]. 
Table 1 Sugarcane accessions and their parents used in the genome-wide association study of cane yield and sugar content

\begin{tabular}{|c|c|c|c|c|c|c|c|}
\hline & Accession & Female parent & Male parent & & Accession & Female parent & Male parent \\
\hline 1. & TUC 01-39 & LCP 85-384 & LCP $82-90$ & 45. & TUC 03-17 & Unknown & Unknown \\
\hline 2. & TUC 01-40 & TUC 89-5 & HOCP 91-552 & 46. & TUC 03-18 & Unknown & Unknown \\
\hline 3. & TUC 01-41 & HOCP 85-845 & S89-P28 & 47. & TUC 03-19 & Unknown & Unknown \\
\hline 4. & TUC 01-42 & TUC 84-31 & HOCP 91-552 & 48. & TUC 03-20 & LCP 85-376 & HOCP 91-552 \\
\hline 5. & TUC 01-43 & CP 79-318 & HOCP 91-552 & 49. & TUC 03-21 & HOCP 92-648 & TUC 77-42 \\
\hline 6. & TUC 01-44 & CP 79-318 & HOCP 91-552 & 50. & TUC 03-22 & HOCP 92-648 & TUC 77-42 \\
\hline 7. & TUC 01-45 & TUC 90-5 & HOCP 94-856 & 51. & TUC 03-23 & HOCP 91-555 & TUC 91-11 \\
\hline 8. & TUC 01-46 & HOCP 91-555 & TUC 89-30 & 52. & TUC 03-24 & LCP 81-281 & TUC 77-42 \\
\hline 9. & TUC 01-47 & HOCP 92-624 & HOCP 91-552 & 53. & TUC 03-25 & L 95-466 & TUC 72-16 \\
\hline 10. & TUC 01-48 & HOCP 93-746 & TUC 77-16 & 54. & TUC 03-26 & TUC 89-28 & TUC 91-2 \\
\hline 11. & TUC 02-27 & HOCP 92-631 & TUC 93-16 & 55. & TUC 03-27 & НОСР 91-559 & HOCP 91-552 \\
\hline 12. & TUC 02-29 & HOCP 92-675 & LCP 82-89 & 56. & TUC 03-28 & CP 65-350 & HOCP 93-754 \\
\hline 13. & TUC 02-30 & TUC 89-32 & CP 57-617 & 57. & TUC 03-29 & L 94-433 & CP 88-2377 \\
\hline 14. & TUC 02-31 & FAM 89-604 & LCP 85-384 & 58. & TUC 01-49 & Unknown & Unknown \\
\hline 15. & TUC 02-32 & RA 89-60 & LCP 85-384 & 59. & TUC 02-63 & Unknown & Unknown \\
\hline 16. & TUC 02-34 & TUC 87-2 & TUC 77-42 & 60 & TUC 02-64 & CP 88-1162 & LCP 85-384 \\
\hline 17. & TUC 02-35 & HOCP 91-555 & HOCP 92-64 & 61. & TUC 02-65 & CP 88-1162 & LCP 85-384 \\
\hline 18. & TUC 02-36 & HOCP 93-746 & TUC 87-5 & 62. & TUC 02-67 & HOCP 94-806 & TUC 89-30 \\
\hline 19. & TUC 02-37 & TUC 87-2 & L 91-264 & 63. & TUC 02-68 & HOCP 94-806 & TUC 89-30 \\
\hline 20. & TUC 02-38 & TUC 87-2 & L 91-264 & 64. & TUC 02-69 & HOCP 94-806 & LCP 85-384 \\
\hline 21. & TUC 02-39 & HOCP 91-555 & TUC 93-1 & 65. & TUC 02-70 & LCP 85-384 & HOCP 83-750 \\
\hline 22. & TUC 02-40 & HOCP 94-806 & TUC 89-30 & 66. & TUC 03-30 & L 89-113 & LCP 85-384 \\
\hline 23. & TUC 02-41 & LCP 85-384 & HOCP 83-750 & 67. & TUC 03-31 & TUC 92-3 & HO 94-856 \\
\hline 24. & TUC 02-42 & TUC 91-1 & LCP 85-384 & 68. & TUC 03-32 & TUC 92-3 & HO 94-856 \\
\hline 25. & TUC 02-43 & LCP 82-89 & HOCP 94-806 & 69. & TUC 03-33 & TUC 92-3 & HO 94-856 \\
\hline 26. & TUC 02-44 & L 90-178 & TUC 93-1 & 70 & TUC 04-1 & Unknown & Unknown \\
\hline 27. & TUC 02-45 & HOCP 85-845 & НОСР 95-961 & 71. & TUC 04-2 & Unknown & Unknown \\
\hline 28. & TUC 02-46 & HOCP 85-845 & НОСР 95-961 & 72. & TUC 04-3 & TUC 77-42 & LCP 85-384 \\
\hline 29. & TUC 02-47 & HOCP 85-845 & HOCP 95-961 & 73. & TUC 04-4 & TUC 93-87 & TUC 77-42 \\
\hline 30. & TUC 02-48 & HOCP 85-845 & HOCP 95-961 & 74. & TUC 04-5 & TUC 93-8 & LCP 85-384 \\
\hline 31. & TUC 02-49 & HOCP 85-845 & HOCP 95-961 & 75. & TUC 04-6 & TUC 93-98 & TUC 87-3 \\
\hline 32. & TUC 02-50 & Unknown & Unknown & 76. & TUC 04-7 & LCP 85-384 & TUC 77-42 \\
\hline 33. & TUC 02-51 & Unknown & Unknown & 77. & HOCP 00-950 & HOCP 93-750 & HOCP 92-676 \\
\hline 34. & TUC 02-52 & Unknown & Unknown & 78. & TUC 01-55 & НОСР 92-624 & TUC 72-716 \\
\hline 35. & TUC 02-53 & Unknown & Unknown & 79. & TUC 01-56 & HOCP 85-845 & HOCP 92-631 \\
\hline 36. & TUC 02-54 & Unknown & Unknown & 80. & TUC 02-71 & TUC 89-29 & HOCP 92-631 \\
\hline 37. & TUC 02-55 & Unknown & Unknown & 81. & TUC 03-34 & L 89-113 & TUC 87-3 \\
\hline 38. & TUC 02-56 & Unknown & Unknown & 82. & TUC 03-35 & HOCP 92-631 & TUC 72-16 \\
\hline 39. & TUC 02-57 & Unknown & Unknown & 83. & TUC 03-36 & TUC 93-98 & RA 89-604 \\
\hline 40. & TUC 02-58 & RA 87-2 & L 91-264 & 84. & TUC 03-37 & TUC 92-3 & HO 94-856 \\
\hline 41. & TUC 02-59 & TUC 89-32 & LCP 82-89 & 85. & TUC 03-39 & HOCP 92-648 & TUC 87-5 \\
\hline 42. & TUC 02-60 & LCP 94-806 & LCP 85-384 & 86. & TUC 03-43 & HOCP 92-675 & TUC 71-7 \\
\hline 43. & TUC 02-61 & HOCP 91-555 & TUC 95-23 & 87. & LCP 85-384 & CP $77-310$ & CP 77-407 \\
\hline 44. & TUC 02-62 & TUC 89-28 & L 94-424 & 88. & TUCCP 77-42 & CP 71-321 & US 72-19 \\
\hline
\end{tabular}




\section{Genotyping}

DNA was extracted from frozen leaf tissue following the Diversity Arrays Technology (DArT) Pty Ltd (Yarralumla, Australia) protocol [41]. The quality and quantity of DNA were verified on a $0.8 \%$ agarose gel. All clones were genotyped using DArT [1] and TRAP markers [21, 22]. DArT genotyping of the population mapping was carried out by DArT Pty Ltd with the Sugarcane High Density 1.0 array. This service involves two methods of complexity reduction (both based on PstI-based methyl filtration) against the array containing 7680 probes. TRAP genotyping was carried out according to [22] with minor modifications. All PCR reactions were carried out in our lab and performed in a Bio-Rad My clycler Termalcycler (Hercules, CA, USA) in $5 \mu \mathrm{l}$ reaction containing 50 ng DNA sample, 10X reaction buffer (Fermentas, Spain, EU), $2.5 \mathrm{mM}$ $\mathrm{MgCl}_{2}$ (Fermentas), $0.088 \mathrm{mM}$ of each dATP, dTTP and dGTP, $0.072 \mathrm{mM}$ of dCTP, $0.16 \mu \mathrm{M}$ of each primer (Table 2), and $0.5 \mathrm{U}$ of Taq DNA polymerase (Fermentas). Different concentrations of Cy5.5-dCTP (GE Healthcare, Buckinghamshire, UK) were included in the reaction depending on the primer combination (Table 2). Amplifications were performed by initially denaturing the template DNA at $94{ }^{\circ} \mathrm{C}$ for $2 \mathrm{~min}$, followed by five cycles at $94{ }^{\circ} \mathrm{C}$ for $45 \mathrm{~s}, 35{ }^{\circ} \mathrm{C}$ for $45 \mathrm{~s}$, and $72{ }^{\circ} \mathrm{C}$ for $1 \mathrm{~min}, 35$ cycles at $94{ }^{\circ} \mathrm{C}$ for $45 \mathrm{~s}, 50{ }^{\circ} \mathrm{C}$ for $45 \mathrm{~s}$, and $72{ }^{\circ} \mathrm{C}$ for $1 \mathrm{~min}$, and a final extension step at $72{ }^{\circ} \mathrm{C}$ for $7 \mathrm{~min}$. Loading dye was added and $0.3 \mu \mathrm{l}$ PCR products were separated on a $25 \mathrm{~cm}$ polyacrylamide gel (Amersham Biosciences) (0.25 mm thick) in a LI-COR 4300 DNA Analyzer (LICOR Biosciences, Lincoln, NE, USA) according to manufacturer's instructions. Images were captured with slow scan laser at $700 \mathrm{~nm}$ and analyzed with the SAGA ${ }^{\mathrm{TM}}$ software (LICOR Biosciences). The product sizes were determined by comparison with molecular weight marker LI-COR IRDye 50-700 bp Size Standard (LICOR Biosciences). TRAP markers, classified as 1 (presence) or 0 (absence), and the binary data from DArT were used for association analysis. All markers with a minor allele frequency (MAF) lower than 0.1 were excluded from the GWAS analysis.

\section{Genetic diversity and population structure}

All polymorphic DArT and TRAP markers scored on the 88 sugarcane accessions were used to estimate genetic relationship among clones. Genetic dissimilarities between all pairwise combinations of clones were calculated using the Dice index [42]. Then, a Neighbor Joining tree was built from the matrix of pairwise dissimilarities using the Darwin software V.5.0.158 [43].

In order to detect and correct for population structure, a PCA was carried out using a subset of 107 DArT markers. All the available markers were not included in this analysis mainly because using the same markers to estimate population structure and then including them in the model to test for an association could create a dependency among terms in the model absorbing some of the QTL effects [44]. The markers used for PCA were sampled according to their position on different Linkage Groups of the Homology Groups of a sugarcane map recently published [45].

\section{GWAS analysis}

A mainstream mixed model GWAS analysis was conducted following [19] and [46]. Associations between molecular markers and quantitative traits were determined following the general linear mixed model for each year:

$$
\mathrm{Y}=\mathrm{X}+\underline{\mathrm{Q}}+\mathrm{e}
$$

where $\mathrm{Y}$ is the phenotypic means vector (i.e. BLUEs from field analysis), $\mathrm{X}$ is the incidence matrix of molecular markers, $\beta$ is the vector of parameters related to the simple regression of the markers on the phenotypes, $Q$ are the eigenvectors of the significant axes of the PCA matrix, $v$ is a vector of predicted values of population structure, and e is the vector of random errors. The PCA scores were used in the model as random components following [19] and [46]. Modeling population structure as random effects not only does the relatedness matrix capture population structure, but also encodes a wider range of structures, including cryptic relatedness and family structure $[36,47,48]$. The significant PC axes included in the model were determined with the TracyWidom statistic [46]. The analyses were performed using R-code developed by the author's with modifications from the emma [49] and GAPIT [50] packages and recently published [40] using the $\mathrm{R}$ software 3.0.0. The code will be uploaded to the R-Cran repository as $m m Q T L$ package [51]. Briefly, a two-step approach was followed to arrive to a multi-QTL model. First, a

Table 2 Conditions for sugarcane TRAP genotyping used in the GWA study of sugarcane breeding population

\begin{tabular}{|c|c|c|c|c|c|}
\hline \multirow[t]{2}{*}{ TRAP } & \multicolumn{2}{|l|}{ Primer forward } & \multicolumn{2}{|c|}{ Primer reverse } & \multirow[t]{2}{*}{${ }^{\mathrm{a} C y 5.5-d C T P}[\mu \mathrm{M}]$} \\
\hline & Name & Sequence $\left(3^{\prime}->5^{\prime}\right)$ & Name & Sequence $\left(3^{\prime}->5^{\prime}\right)$ & \\
\hline T14 & SuPS/ Sucrose phosphate synthase & CGACAACTGGATCAACAG & Arbi-2 & GACTGCGTACGAATTGAC & 0.8 \\
\hline T15 & SuPS/ Sucrose phosphate synthase & CGACAACTGGATCAACAG & Arbi-3 & GACTGCGTACGAATTTGA & 0.5 \\
\hline $\mathrm{T} 17$ & DirH/ Dirigent protein & TGGAGATTTTGGAGGAAC & Arbi-2 & GACTGCGTACGAATTGAC & 0.5 \\
\hline
\end{tabular}

${ }^{a}$ Final concetration of Cy5.5-dCTP in reaction 
marker-by-marker scan of the genome was conducted to identify significant marker-trait associations with a falsediscovery rate $(F D R)(\alpha=0.05)$ to control for multiple testing. Since a large number of significant marker-trait associations were found, and to report the more relevant QTL, a second pruning of markers with a more stringent FDR P-value (0.01) was conducted. Second, all significant markers were fitted in a single final multi-QTL model adding markers at a time in a stepwise-forward selection manner to control for residual QTL and to identify QTL following [52-54]. The Wald statistic with a liberal $\mathrm{P}$-value $<0.01$ following $[19,36]$ was used for this model.

QQ-plots assuming a uniform distribution of P-values under the null-hypothesis of no-QTL (i.e., Schwederand Spjøtvoll plots; [55]) were used to evaluate the models. Briefly, the observed P-values values are plotted against the expected theoretical values (i.e. cumulative density function) for a uniform distribution. This is standard methodology to evaluate the models ability to control for spurious association $[17,36,56]$. These analyses were also performed in $\mathrm{R}$ statistical software.

\section{Analysis of sugarcane DArT marker sequences associated to important traits}

Sequences from sugarcane DArT markers significantly associated with CY or SC at least in 2 years of study and DArT markers significantly associated with a trait in the multi-QTL model that resulted in highest Allelic Substitution Effect (ASE) were used to determine their similarity and position on the sorghum genome. This was conducted by using BLASTN 2.2.22 [57] on non-redundant databases of sorghum sequences with different algorithms. First, "Megablast" was employed to identify query sequences. In the cases where no significant similarity was found, a second algorithm "Discontiguous megablast" was chosen since it uses an initial seed that ignores some bases and is intended for cross-species comparisons. Finally, when no significant similarity was found using the second algorithm, BLAST was performed using "blastN".

\section{Results}

Phenotypic data, molecular markers, panel diversity and population structure

The 88 sugarcane clones used in this study were phenotyped by SCBP-EEAOC for CY and SC during 2009, 2010 and 2011 and genetically characterized by DArT and TRAP markers. The BLUE values obtained with the adjusted model, described above, were 48 to $85 \mathrm{t} \mathrm{ha}^{-1}$ for CY and 9.2 to $10.9 \%$ for SC (Table 3 and Additional file 2). The genetic correlations observed between years for CY were 0.60 for 2009 and 2010, 0.78 for 2010 and 2011, and 0.50 between 2009 and 2011. Meanwhile, genetic correlations observed between years for SC were
Table 3 Descriptive statistics of cane yield (CY) and sugar content (SC) from field trial of all genotypes evaluated in the GWA study

\begin{tabular}{llllll}
\hline & \multicolumn{2}{l}{$\mathrm{CY}\left(\mathrm{t} \mathrm{ha}^{-1}\right)$} & & \multicolumn{2}{l}{$\mathrm{SC}(\%)$} \\
\cline { 2 - 3 } & Mean & $\mathrm{CV}$ & & Mean & $\mathrm{CV}$ \\
\hline Plant-cane (2009) & 47.70 & 0.20 & & 9.22 & 0.08 \\
First ratoon (2010) & 75.14 & 0.13 & & 10.62 & 0.06 \\
Second ratoon (2011) & 84.95 & 0.12 & & 10.88 & 0.06 \\
\hline
\end{tabular}

$\mathrm{CV}$ coefficient of variation

0.40 for 2009 and 2010, 0.72 for 2010 and 2011, and 0.46 between 2009 and 2011. There were low correlations between CY and SC across years $(-0.06,-0.24$ and -0.14 for 2009, 2010 and 2011, respectively), being only significant $(P$-value $<0.05)$ correlation among CY 2010 and SC 2010 (Additional file 3). Results of broad-sense heritability for both trait and location are presented in Table 4. CY was under strong genetic control, since estimates of broadsense heritability were high, ranging from 0.51 to 0.84 . Estimates of $\mathrm{H}^{2}$ for $\mathrm{SC}$ were also high (from 0.55 to 0.80 ), with the only exception for SC 2010 with a moderate value of $\mathrm{H}^{2}$ of 0.30 . This high estimates of heritability indicated that the field trials produced good-quality data for the association study.

Out of the 7680 probes evaluated in the DArT array, 1642 markers were informative (i.e. polymorphic, with a MAF higher than 0.10). Out of the 177 TRAP markers evaluated, only 103 markers were included in the GWAS and 74 were excluded because the MAF was lower than 0.1. Among the 1642 informative DArT markers, 258 were mapped on the recently published sugarcane genetic map [45].

Diversity analysis using all the informative TRAP and DArT markers revealed no particular structure in the mapping population (Fig. 1 and Additional file 4; http:// dx.doi.org/10.5061/dryad.mv88m). The most closely related clones (parent-descendant or full-sib) were grouped in the same area of the neighbor-joining tree. However, they do not form outstanding branches. Surprisingly, there were two exceptions where full-sib

Table 4 Broad-sense heritability $\left(\mathrm{H}^{2}\right)$ at each location and at each crop cycle for Cane Yield and Sugar Content

\begin{tabular}{llcc}
\hline $\begin{array}{l}\text { Crop } \\
\text { cycle }\end{array}$ & Traits & Location & \\
\cline { 3 - 4 } & & Cerco Represa & Santa Ana \\
\hline Plant & Cane Yield 2009 & 0.747 & 0.513 \\
& Sugar Content 2009 & 0.666 & 0.618 \\
Ratoon 1 & Cane Yield 2010 & 0.758 & 0.649 \\
& Sugar Content 2010 & 0.553 & 0.301 \\
Ratoon 2 & Cane Yield 2011 & 0.699 & 0.835 \\
& Sugar Content 2011 & 0.800 & 0.596 \\
\hline
\end{tabular}




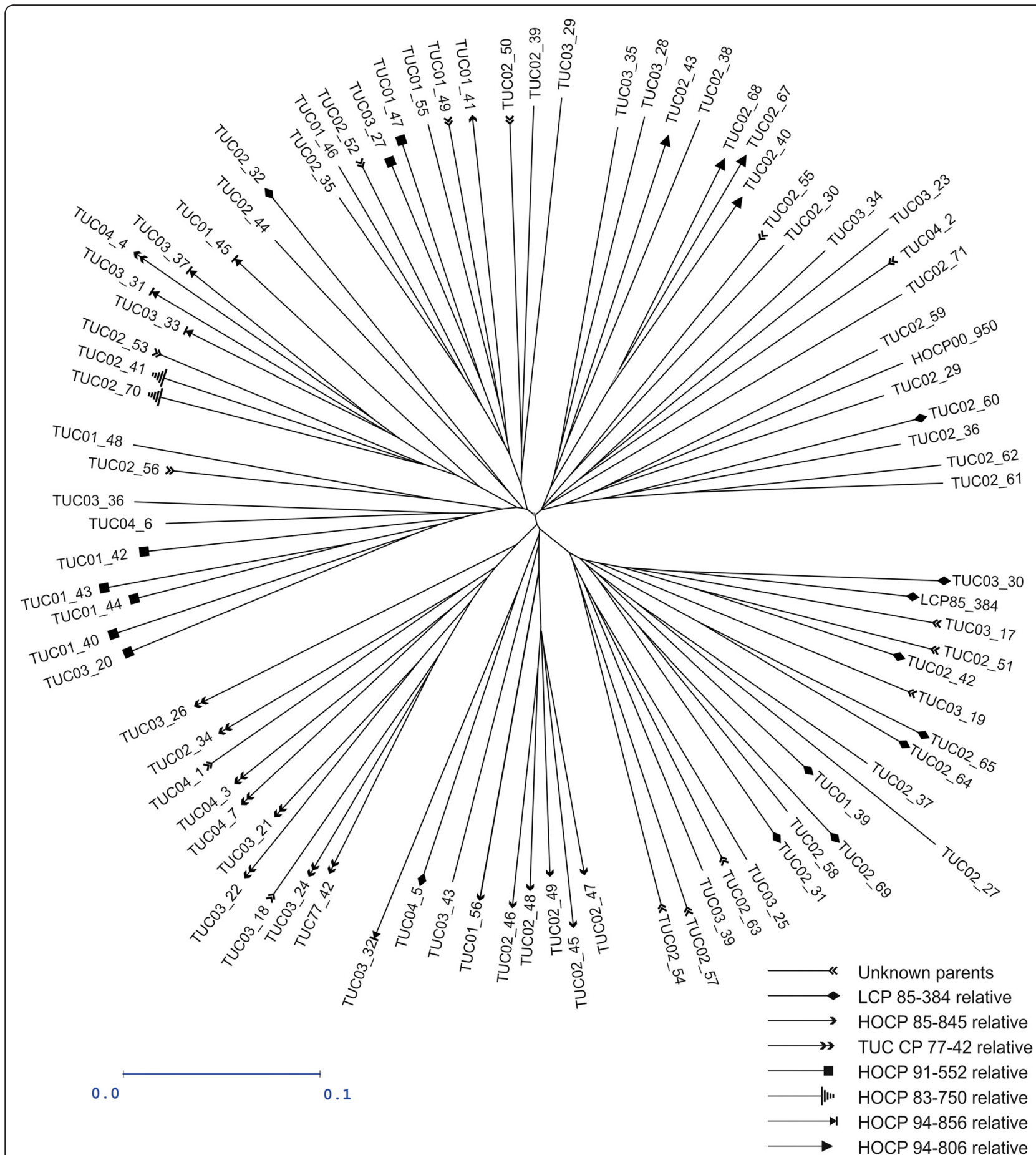

Fig. 1 Neighbour-joining tree based on the Dice dissimilarity index calculated from 1745 polymorphic markers data (103 TRAP and 1642 DArT) assembling the 88 sugarcane genotypes

clones were located in different branches, i.e. TUC 0238 and TUC 02-37 whose genealogical records indicate that they are descendant from the same parents; and TUC 03-32 that would be full-sib with TUC 03-31, TUC 03-33, TUC 03-37 and TUC 04-4, and grouped separately from the rest. At the most distant branch, located at the lower right portion of the tree, grouped LCP 85384 and most of the clones derived from this variety. At the lower center position of the tree, clones derived from HOCP 85-845 were grouped. Then, at the lower left portion of the tree, TUCCP 77-42 and clones derived from this variety were located. On the other hand, the first three 
axes of the PCA using 107 DArT markers distributed across the sugarcane genome were significant following the Tracy-Widom statistic. The PCA scores for each genotype at each axes were included as random covariates in the GWAS model to model the variance-covariance matrix among genotypes. The first two axes explained 7.47 and $4.99 \%$ of the total variation, respectively (Fig. 2). The first axis could be associated to filial relations; where two groups seems associated to LCP 85-384 offspring (right side of the PC1 axis) and non-LCP 85-384 offspring (left side of the PC1 axis). At PC2 level, TUCCP 77-42 variety was distant from the rest of the genotypes. Results showed at Fig. 2 are congruent with those previously mentioned in Fig. 1, since clone descendant from LCP 85-384 were detached from the rest of genotypes.

\section{GWAS analysis}

GWAS analysis was conducted by using 1638 discrete markers (1535 DArT and 103 TRAP). QQ-plots of Pvalues showed that population structure was properly accounted for by using a stratified selection of markers to correct for population structure as random effect (Additional file 5). In the present study, 43, 42 and 41 markers significantly associated (FDR $\alpha=0.01$ ) with $\mathrm{CY}$ in 2009 (cane plant), 2010 (first ratoon) and 2011 (second ratoon), respectively, were found. In addition, 38, 34 and 47 significant marker-trait associations for SC were detected, in 2009 (cane plant), 2010 (first ratoon) and 2011 (second ratoon), respectively (Additional file 6). Certain stability across crop-cycles was observed since twenty markers were found to be associated with $\mathrm{CY}$ in 2 years of study, being the coincidence between 2010 and 2011 (first and second ratoon) more frequent. For SC, one marker-trait association was found significant for the 3 years of study, while twelve markers presented association for 2 years. These association were also more frequent when 2010 and 2011 years were involved (Table 5). Mostly markers associated with one trait were not associated with the other; however, four markers were associated with both traits (M54 for CY-2010, CY2011 and SC-2011; M58 for CY-2010, CY-2011 and SC2011; M173 for CY-2010, SC-2010 and SC-2011; and, M188 for CY-2010, SC-2010 and SC-2011).

A multi-QTL model by year was constructed with markers significantly associated with each trait. Considering the 3 years, 23 markers were significant in the multi-QTL for CY while 21 remained significant in the multi-QTL for SC (Table 6). For CY, markers M100, M120, M140, M200 and M202 had allelic substitution effect (ASE) larger than $8.33 \mathrm{t} \mathrm{ha}^{-1}$. For SC, M28, M51 and M171 had ASE larger than $0.70 \%$. Marker M64 was detected in more than 1 year in the multi-QTL model (SC 2010 and 2011). The effect of this marker was the same in the 2 years of association and $57 \%$ of the genotypes analyzed had the favorable allele for this marker.

\section{Sugarcane DArT markers sequences on sorghum genome} The 27 available sequences of DArT markers significantly associated with a trait in at least 2 years of study were blasted to the sorghum genome sequence database (Table 5). When the sequences of sugarcane DArT markers were analyzed, three of them were found to present the same nucleotide sequence. This was useful as internal control because genotypes presented the

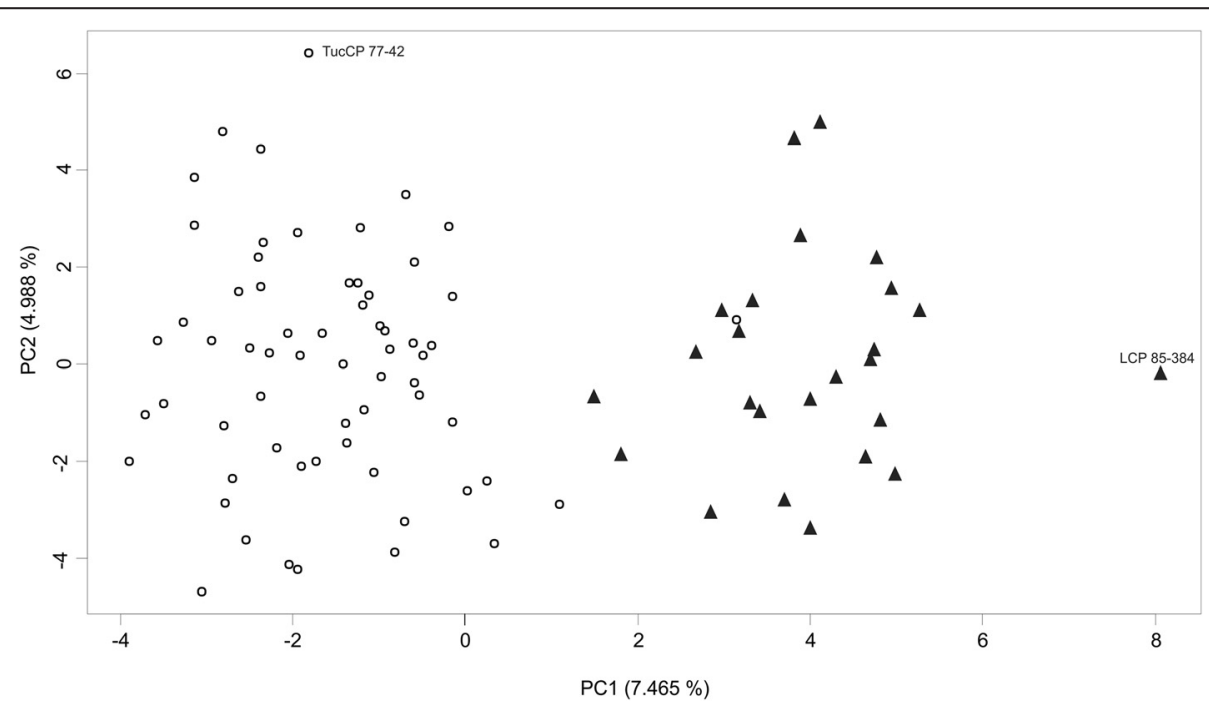

Fig. 2 The top two axes of variation of 88 sugarcane clones studied resulting of Principal Component Analysis by using 107 DArT markers distributed across the genome. The percentage of variation represented by each component is in parentheses. Accessions are colored according to their parentage with LCP 85-384. Progeny of LCP 85-384 are in black triangle ( $\mathbf{\Delta})$; the remaining genotypes are in empty circles (O) 
Table 5 Summary of results found for markers associated with traits of interest at least in two years of study and comparison with sorghum genome

\begin{tabular}{|c|c|c|c|c|c|c|c|c|c|c|c|c|c|c|}
\hline \multirow[t]{2}{*}{ Locus } & \multicolumn{3}{|c|}{ Cane Yield } & \multicolumn{3}{|c|}{ Sugar Content } & \multirow{2}{*}{$\begin{array}{l}\text { DArT } \\
\text { sequence } \\
\text { size }(\mathrm{pb})\end{array}$} & \multirow{2}{*}{$\begin{array}{l}\text { BLAST } \\
\text { algorithm } \\
d\end{array}$} & \multirow{2}{*}{$\begin{array}{l}\text { Result from } \\
\text { alignament with } S \text {. } \\
\text { bicolor }\end{array}$} & \multirow[t]{2}{*}{ Identity } & \multirow[t]{2}{*}{ Expect } & \multirow[t]{2}{*}{ Locus tag } & \multirow{2}{*}{$\begin{array}{l}\text { Sorghum } \\
\text { chromosome }\end{array}$} & \multirow[t]{2}{*}{ GenBank ID } \\
\hline & 2009 & 2010 & 2011 & 2009 & 2010 & 2011 & & & & & & & & \\
\hline$\overline{\mathrm{M} 151}$ & * & & * & & & & 748 & blastn & hypothetical protein & $49 / 64(77 \%)$ & 0.001 & Sb01g041060 & 1 & XM_002468130.1 \\
\hline M97 & & * & * & & & & 456 & $\mathrm{~m}$ blast & hypothetical protein & 419/459(91\%) & $9.00 \mathrm{E}-173$ & Sb02g004780 & 2 & XM_002461519.1 \\
\hline M41 & & & & & * & $* *$ & 263 & blastn & hypothetical protein & $45 / 58(78 \%)$ & 0.25 & Sb02g028450 & 2 & XM_002460412.1 \\
\hline M91 & * & * & & & & & 404 & $\mathrm{dm}$ blast & hypothetical protein & $68 / 68(100 \%)$ & $1.00 \mathrm{E}-27$ & Sb03g004640 & 3 & XM_002457229.1 \\
\hline M64 & & & & * & * & * & 291 & $\mathrm{~m}$ blast & hypothetical protein & 287/291(99 \%) & $6.00 \mathrm{E}-143$ & Sb03g035700 & 3 & XM_002456357.1 \\
\hline M78 & & & & * & & * & 474 & $\mathrm{~m}$ blast & hypothetical protein & 79/83(95 \%) & $4 \mathrm{E}-30$ & Sb04g025280 & 4 & XM_002452369.1 \\
\hline M125 & & * & * & & & & 1048 & dm blast & hypothetical protein & $87 / 121(72 \%)$ & $9 \mathrm{E}-08$ & Sb05g000890 & 5 & XM_002448838.1 \\
\hline M95 & & * & * & & & & $545^{\mathrm{a}}$ & $\mathrm{dm}$ blast & hypothetical protein & $122 / 146(84 \%)$ & $2 \mathrm{E}-37$ & Sb06g014780 & 6 & XM_002447689.1 \\
\hline M50 & & * & * & & & & $545^{\mathrm{a}}$ & dm blast & hypothetical protein & $122 / 146(84 \%)$ & $2 \mathrm{E}-37$ & Sb06g014780 & 6 & XM_002447689.1 \\
\hline M120 & & * & * & & & & 457 & $\mathrm{~m}$ blast & hypothetical protein & 407/435(94 \%) & 0 & Sb06g000450 & 6 & XM_002445961.1 \\
\hline M57 & & & & & * & $* * *$ & 60 & blastn & hypothetical protein & $20 / 21(95 \%)$ & 0.34 & Sb06g000690 & 6 & XM_002445988.1 \\
\hline M189 & & * & * & & & & 355 & blastn & hypothetical protein & 18/18(100\%) & 1.2 & Sb06g025190 & 6 & XM_002448276.1 \\
\hline M46 & * & * & & & & & $371^{b}$ & $\mathrm{~m}$ blast & hypothetical protein & $119 / 121(98 \%)$ & $4 \mathrm{E}-54$ & Sb07g020840 & 7 & XM_002444326.1 \\
\hline M30 & * & $* *$ & & & & & $384^{\mathrm{b}}$ & $\mathrm{m}$ blast & hypothetical protein & 119/121(98 \%) & $4 \mathrm{E}-54$ & Sb07g020840 & 7 & XM_002444326.1 \\
\hline M71 & & * & * & & & & 425 & blastn & hypothetical protein & $59 / 73(81 \%)$ & 3.00E-09 & Sb08g022800 & 8 & XM_002443601.1 \\
\hline M58 & & $* *$ & * & & & * & $566^{c}$ & $\mathrm{~m}$ blast & hypothetical protein & $354 / 371(95 \%)$ & $7 E-168$ & Sb09g002270 & 9 & XM_002439164.1 \\
\hline M54 & & $* *$ & $*$ & & & * & $566^{c}$ & $\mathrm{~m}$ blast & hypothetical protein & $354 / 371(95 \%)$ & $7 E-168$ & Sb09g002270 & 9 & XM_002439164.1 \\
\hline M168 & & & & * & * & & 384 & $\mathrm{~m}$ blast & hypothetical protein & $368 / 384(96 \%)$ & 7E-176 & Sb09g015250 & 9 & XM_002440847.1 \\
\hline M59 & & * & * & & & & 468 & blastn & hypothetical protein & $23 / 25(92 \%)$ & 0.13 & Sb09g007900 & 9 & XM_002439437.1 \\
\hline M193 & & $*$ & $* *$ & & & & 604 & blastn & hypothetical protein & 18/18(100\%) & 2.1 & Sb09g014225 & 9 & XM_002439535.1 \\
\hline M153 & & & & & * & * & 753 & $\mathrm{dm}$ blast & hypothetical protein & 85/87(98 \%) & $6 \mathrm{E}-35$ & Sb10g006890 & 10 & XM_002437984.1 \\
\hline M14 & & & & & $*$ & * & 427 & blastn & hypothetical protein & $23 / 24(96 \%)$ & 0.43 & Sb10g010770 & 10 & XM_002438218.1 \\
\hline M188 & & $*$ & & & * & * & 578 & blastn & hypothetical protein & 29/34(85\%) & 0.59 & Sb10g023910 & 10 & XM_002437224.1 \\
\hline M45 & & & & $* *$ & & * & 749 & blastn & alpha kafirin & 79/98(81 \%) & $3.00 \mathrm{E}-18$ & unassigned & & Y17556.1 \\
\hline M181 & & & & $* *$ & & * & 749 & blastn & alpha kafirin & $46 / 46(100 \%)$ & $5 E-16$ & unassigned & & Y17556.1 \\
\hline M108 & * & & $*$ & & & & 488 & $\mathrm{~m}$ blast & alpha kafirin & 61/62(98 \%) & $7 E-23$ & unassigned & & Y17556.1 \\
\hline M173 & & * & & & * & * & 662 & blastn & alpha kafirin & 39/41(95\%) & $5 E-09$ & unassigned & & Y17556.1 \\
\hline
\end{tabular}


Table 5 Summary of results found for markers associated with traits of interest at least in two years of study and comparison with sorghum genome (Continued)

M198* * na

M197 ** * na

M203 * * na

na not available sequence

FDR P-values: * $p<0.01$; ** $p<0.001$; and *** $p<0.0001$

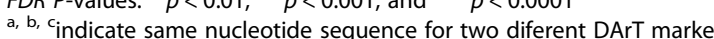

${ }^{d}$ megablast ( $m$ blast), discontiduous mega blast (dm blast) or blastn

megablast ( $\mathrm{m}$ blast), discontiduous mega blast ( $\mathrm{dm}$ blast) or blastn
Data in bold $=$ more significant alignment i.e. larger sequence size with high identity and lower Expected value 
Table 6 Significant markers associated to cane yield and sugar content and their allelic substitution effect (ASE) in the multi-QTL model for the sugarcane GWAS panel

\begin{tabular}{|c|c|c|c|c|c|c|c|c|}
\hline \multicolumn{9}{|c|}{ Cane Yield } \\
\hline \multicolumn{3}{|l|}{2009} & \multicolumn{3}{|l|}{2010} & \multicolumn{3}{|l|}{2011} \\
\hline locus & $\mathrm{ASE}^{\mathrm{a}}$ & $P$ - value ${ }^{b}$ & locus & $\mathrm{ASE}^{\mathrm{a}}$ & $P$ - value ${ }^{b}$ & locus & $\mathrm{ASE}^{\mathrm{a}}$ & $P$-value \\
\hline M155 & 4.11 & 0.00859 & M120 & -8.70 & 0.00001 & M100 & 8.69 & 0.00013 \\
\hline M17 & 5.35 & 0.00114 & M140 & 9.91 & 0.00002 & M105 & -4.78 & 0.00692 \\
\hline M185 & 7.18 & 0.00012 & M188 & 4.19 & 0.01031 & M131 & 6.36 & 0.00028 \\
\hline M200 & -8.36 & 0.00001 & M189 & 5.52 & 0.01048 & M145 & -4.19 & 0.02756 \\
\hline M30 & -4.41 & 0.01525 & M197 & 7.29 & 0.00007 & M166 & 4.17 & 0.01292 \\
\hline \multirow[t]{5}{*}{ M35 } & -6.00 & 0.00464 & M59 & -4.71 & 0.00441 & M193 & -4.71 & 0.01644 \\
\hline & & & M72 & -8.22 & 0.00002 & M202 & 8.92 & 0.00001 \\
\hline & & & & & & M47 & 5.51 & 0.00361 \\
\hline & & & & & & M98 & -7.47 & 0.00694 \\
\hline & & & & & & M99 & 6.65 & 0.01779 \\
\hline \multicolumn{9}{|c|}{ Sugar Content } \\
\hline 2009 & & & 2010 & & & 2011 & & \\
\hline locus & $\mathrm{ASE}^{\mathrm{a}}$ & $P$ - value ${ }^{b}$ & locus & $\mathrm{ASE}^{\mathrm{a}}$ & $P$-value ${ }^{b}$ & locus & $\operatorname{ASE}^{\mathrm{a}}$ & $P$ - value \\
\hline M147 & 0.3 & 0.04552 & M103 & -0.3 & 0.00728 & M101 & -0.53 & 0.00001 \\
\hline M156 & -0.54 & 0.00011 & M124 & -0.31 & 0.00873 & M15 & 0.42 & 0.00293 \\
\hline M181 & 0.55 & 0.00011 & M153 & 0.42 & 0.01627 & M150 & -0.22 & 0.04433 \\
\hline \multirow[t]{6}{*}{ M28 } & -0.81 & 0.00005 & M171 & -0.76 & 0.0000002 & M194 & 0.29 & 0.01277 \\
\hline & & & M177 & -0.38 & 0.00374 & M205 & -0.38 & 0.00293 \\
\hline & & & M183 & -0.23 & 0.06801 & M51 & 0.71 & 0.00006 \\
\hline & & & M206 & 0.33 & 0.01723 & M64 & -0.48 & 0.00017 \\
\hline & & & M5 & 0.4 & 0.00181 & M86 & 0.25 & 0.02331 \\
\hline & & & M64 & -0.48 & 0.00003 & & & \\
\hline
\end{tabular}

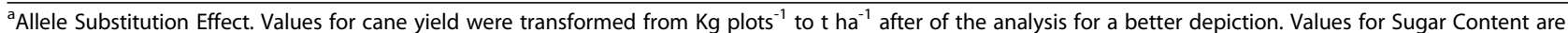
expressed in \%. Negative sign indicate that the absence of the marker is the desirable allele

${ }^{\mathrm{b}} \mathrm{P}$-value of individual markers in the multi-QTL model

same configuration (absence or presence) for markers with the same sequence. Most of alignments involved sequences of hypothetical proteins of sorghum showing a high identity and low e-values. Noticeably M120 showed a high identity (94\%) with a sorghum sequence located on chromosome 6 with an e-value of 0 , indicating that there is no probability of alignments with scores equivalent to or better in a database search by chance.

Similarly, sequences of DArT markers significantly associated with a trait in the multi-QTL model that resulted in highest ASE value (M100, M120 and M140 for CY; M28, M51, M64 and M171 for SC) were blasted to the sorghum genome sequence database. Results are shown in Table 7, markers M120 and M64 were not included since they were already shown in Table 5. Other markers with highest ASE value that were not blasted since no sequence information is available, were TRAP markers M200 and M202, which derive from T15 and T17 amplifications respectively (see Table 2). Interestingly, some DArT markers, mainly associated with SC, showed high identity with an alpha kafirin protein that it is involved in the storage of nutritious substrates.

\section{Discussion}

In the last decade, several approaches tested in plant genetics have allowed the precise identification of "desirables" alleles at molecular level. In the most recent years, the development of association mapping for this purpose has gained large importance. In this work, association mapping was used in sugarcane to identify molecular markers associated with both sugar and biomass yields. The quantitative nature of both traits and the polyploid genome of this crop make the use of association mapping a great challenge compared to other studies conducted for crops with less complex genomes. Even considering that, in the present study we were able to detect QTL for both traits, which are consistent across harvesting seasons. 
Table 7 Results of alignments of markers associated with cane yield and sugar content with higher value of allelic substitution effect (ASE) in the multi-QTL model for the sugarcane GWAS panel against Sorghum bicolor sequences

\begin{tabular}{|c|c|c|c|c|c|c|c|c|}
\hline Trait & Marker & $\begin{array}{l}\text { DArT sequence } \\
\text { size }(p b)\end{array}$ & BLAST algorithm ${ }^{a}$ & $\begin{array}{l}\text { Result from alignment with } \\
\text { S. bicolor }\end{array}$ & Identity & Expect & $\begin{array}{l}\text { Sorghum } \\
\text { chromosome }\end{array}$ & Accesion $\mathrm{N}^{\circ}$ \\
\hline CY 2010 & M140 & 487 & blastn & $\begin{array}{l}\text { Sorghum bicolor clone BAC } \\
88 \mathrm{M} 4 \text {, complete sequence }\end{array}$ & 100/132 (76 \%) & 7.00E-18 & 8 & AY661656.1 \\
\hline CY 2011 & M100 & 318 & blastn & $\begin{array}{l}\text { Sorghum bicolor putative } \\
\text { cytochrome P450-like protein }\end{array}$ & 73/95 (77 \%) & $2.00 \mathrm{E}-10$ & 1 & AF466201.1 \\
\hline SC 2009 & M28 & 470 & $\mathrm{dm}$ blast & alpha kafirin & 59/62 (95 \%) & 1.00E-19 & unassigned & Y17556.1 \\
\hline SC 2010 & M171 & 711 & $\mathrm{~m}$ blast & alpha kafirin & 74/86 (86 \%) & $5.00 \mathrm{E}-21$ & unassigned & Y17556.1 \\
\hline SC 2011 & M51 & 579 & $\mathrm{dm}$ blast & $\begin{array}{l}\text { Sorghum bicolor } \\
\text { hypothetical protein, } \\
\text { mRNA }\end{array}$ & 74/94 (79 \%) & $2.00 \mathrm{E}-14$ & 6 & XM_002448117.1 \\
\hline
\end{tabular}

${ }^{a}$ megablast ( $\mathrm{m}$ blast), discontiduous mega blast (dm blast) or blastn

\section{Population mapping}

Several studies suggest that the use of elite germplasm could be useful for association mapping [58-60], although there are only a few approaches conducted with this type of population in plant crops (see [60] for a review). In order to take advantage of the available large phenotypic data accumulated from replicated field experiments over locations and years for the SCBPEEAOC, association mapping was conducted over accessions of its current elite breeding pool (genotypes of the advanced yield trails). All genotypes characterized in the present study were planted and evaluated at the same time obtaining both balanced data across environments and an extensive phenotyping. Therefore, although population sizes are relatively small, the high quality extensive phenotyping provides a reasonable foundation for the GWAS study. Small population sizes would result in decreased power to detect QTL $[61,62]$ and increased false-positive rate [63, 64]. However, assembling large populations in sugarcane could be a challenge mainly because of the phenotyping requirements and the relative size of the breeding programs. Furthermore, exploring diverse germplasm not adapted to local conditions and with strong population structure could hinder the QTL detection due to the additional challenge of modeling such population structure [65]. Additionally, the mapping approach (i.e., candidate-gene or genomewide), the relatedness of the individuals, the extent of $\mathrm{LD}$, and the number of markers will determine the optimal population size in GWAS studies [60]. Finally, population sizes close to 100 have been used elsewhere as a first approach to QTL mapping in other species [66-70]. Recent sugarcane GWAS studies included 189 and 183 individuals [27, 71]. However, since the experimental population in the present study was a representative sample of the population to which inference is desired, it is expected that the information obtained from the association study will be useful and readily applicable to local crop improvement [6].

\section{Controlling population structure}

The presence of subpopulations in the mapping population creates a challenge for association studies. Several methods have been proposed for dealing with false positives related to population structure [16-18]. In that sense, many studies conducted especially with small datasets and diploid organisms implemented the method proposed in the freely available software Structure [16]. However, in the case of sugarcane considering its complex polyploid genome, several assumptions are not fulfilled for the use of Structure; therefore, the applicability of this algorithm may be limited in sugarcane [72]. For example, in a previous study in sugarcane [73], when population structure was taken into account by using Structure, arbitrary subpopulations of the genotypes were observed; however, as there were no clear discontinuities in the population, this algorithm failed to conclusively group the population [28]. In the present study a GWAS mapping was applied within a mixedmodel framework according to [19] and [46]. Spurious associations were controlled while the power to detect true associations was maximized by using a PCA as a random component to control for population structure $[19,36$, 46-48]. When PCA as a random component is included in the analysis, the large population structure is captured with the first few axes that account for most of the variation while the more subtle relationships among individuals are captured by the remaining significant axes.

Population structure was inferred with an independent set of markers to avoid dependency among terms in the model and to prevent the structure from absorbing the QTL effects from the model $[44,46]$. A sub-set of available markers to infer population structure has been used in other studies [44], including sugarcane [27]. Gouy et al. [27] used a sub-set of the available markers to ensure genome coverage and avoid over-representation of genomic regions. The sugarcane DArT-based map recently published [45] was used to sample independent markers of each linkage group. Furthermore, QQ-plots of $P$ values showed that population structure was properly 
accounted for by using a stratified selection of markers to correct for population structure as random effects (Additional file 5). On the other hand, using a random selection of markers without accounting for marker position failed to properly account for population structure (data not shown). Additionally, the grouping observed at PC1 has a biological interpretation, reflecting genetic variation among progeny (Fig. 2). For instance, the righthand side of the plot includes cv. LCP 85-384 and its progeny; while the left-hand side represents the remaining genotypes. This was also found in other studies, where LCP 85-384 was genetically more distant to modern varieties [74-76]. Cultivar LCP $85-384$ is a $\mathrm{BC}_{4}$ derived line of S. spontaneum US 56-15-8 and therefore have a strong wild genetic component [74]. TUCCP 7742 , another variety with a strong wild genetic component $\left(\mathrm{BC}_{1}\right.$ of S. spontaneum SES 147B), was distant from the rest of the genotypes at PC2 level (Fig. 2). These results showed enough evidence of the ability of these few markers (107) used in the PCA to reveal the genetic background of genotypes. Furthermore, most of the structure found in these genotypes seems to come from subtle kinship relationships more than large-scale population structure. Our method properly accounted for these relationships.

\section{Sugarcane GWAS}

Association studies are becoming a popular strategy for unraveling the genetic underlying complex traits. The first association mapping studies conducted in sugarcane have focused on genome-wide approaches attempted at looking for associations between disease resistance and molecular markers [27, 71, 73, 77, 78]. Few reports were found $[27,28]$ involving associations between molecular markers and traits related with cane and sucrose yield and/or yield components. Wei et al. [28] conducted a study where field-data for cane yield ( $\left.\mathrm{t} \mathrm{ha}^{-1}\right)$ and commercially extractable sucrose content were obtained in plant-cane. However, one of the major concerns in order to find markers contributing to yield during several ages is the repeatability of the marker-trait associations across harvesting seasons (mainly for ratoons). Another study including sucrose yield and yields components, among other traits, was carried out by Gouy et al. [27], obtaining plant-cane phenotypic data from trials planted during different season or years and locations. However, only a few marker-trait associations were detected for the traits analyzed. In that sense, in the present study several markers (20) were found to be associated with $\mathrm{CY}$ in at least 2 years, being more frequent the coincidence among first and second ratoon. Sequences of four markers (M58, M54, M97 and M120) showed very high similitude and low e-value with coding sequences of Sorghum bicolor. Sequences of M58 and M54 were found to be the same, and they presented high identity and low e-value with a sequence located on chromosome 9 from Sorghum bicolor, where QTLs for plant height and tiller number were previously found [79]. Sequence of M97 was located on chromosome 2 of Sorghum bicolor, were QTLs for stem diameter and plant height were previously reported [80] and validated later [79]. Regarding M120 marker, whose effect was $8.70 \mathrm{tha}^{-1}$ in the multi-QTL model, the sequence of this marker presented high similitude with a Sorghum bicolor sequence located on chromosome 6, where QTLs for stem biomass yield, plant height and tiller number were reported in different studies (see [79]).

For SC, one marker-trait association was found significant for the 3 years of study. This marker, M64, showed high identity (99\%) and low e-value (6,00 E-143) with a sequence located in chromosome 3 from Sorghum bicolor, where several QTL related to sugar content were previously reported (Glucose content [80]; Sugar content [81]; Brix ${ }^{\circ}$, Juice Sugars $\mathrm{g} \mathrm{L}^{-1}$ and Juice Sucrose $\mathrm{g} \mathrm{L}^{-1}$ [82]) and validated [79]. Moreover, in our multi-QTL model, M64 showed the same marker effect $(-0.48 \%)$ in two consecutive years (2010 and 2011), indicating that a negative selection for this marker could increase SC.

The highly conserved sequences found in the sorghum genome confirm the usefulness of this database to study regions of interest in sugarcane genome. Sequence of marker M120 presented 407 identical nucleotides with an e-value of zero, suggesting that this is a region shared by sugarcane and sorghum. Other sugarcane sequence markers were also significantly similar to sorghum, which is in agreement with previous studies [24, 25, 83] that reported a high gene microlinearity between sorghum and sugarcane.

Even though this GWAS study is mostly focused on exploring the entire genome with DArT makers, also TRAP markers that targeted to coding regions were employed. This information resulted useful in finding regions controlling traits of interest since three of the 103 TRAP markers used for association analysis were significantly associated with $\mathrm{CY}$ in 2 years of study.

It is important to highlight the challenge in finding strong marker-trait associations in complex polyploid species using dominant markers. It is well known that this type of markers are less informative than co-dominant ones, especially in polyploids, because copies of homologous chromosomes "dilute" the polymorphisms. When the markers are evaluated with a binary system, they are scored as 0 for the absence of the allele, or 1 for the presence of at least one copy of the allele. This constitutes one intrinsic limitation of the method that is associated with overlooking ploidy level [84]. In that sense, further research need to be conducted to investigate the establishment of associations between continuous data 
obtained from DArT markers and allele dosage, instead of binary data. This would probably increase the number of markers associated with characteristics of interest. Moreover, considering that the study was carried out on a panel of sugarcane varieties and elite lines, most favorable alleles would probably be fixed; however, no single variety has all favorable alleles giving an opportunity to accumulate those alleles and thus achieve crop improvement.

\section{Conclusions}

This study demonstrated that association mapping in elite germplasm seems to have a clear potential for improving sugarcane, especially for complex traits such as CY and SC, for which measurements are costly and time consuming. Combining existing phenotypic trial data and genotypic DArT and TRAP marker characterizations within an LD approach using PCA as a random component to control for population structure may prove to be highly successful to find molecular markers significantly associated with the measured traits. Two aspects were key to obtain the results shown here: the high quality of phenotypic data from the EEAOC-SCBP collected in successive crop cycles and under the same environmental conditions for all genotypes; and the adequate selection of markers to be used in the analysis of population structure, since the choice of markers that do not adequately reflect the presence of such structure could hinder the detection of QTLs of interest. Additionally, sequences of DArT marker associated with trait of interest were aligned in chromosomal regions where sorghum QTLs has been previously reported. The whole role of these regions will need to be further investigated.

Even though the small size of the population could affect the power of the GWAS and increase false positive rate [85], findings reports here must be considered early evidence about the genome regions and markers associated with the genetic control of yield-related characteristics in sugarcane and should be further validated.

\section{Additional files}

Additional file 1: Table S1. Sites, geographic coordinates, and

Additional file 2: Table S2. Dataset of BLUE values obtained for each genotype from model adjusted as described in Methods Section. CY = Cane Yield; SC = Sugar Content. Table S3. Marker dataset for each genotype. (XLSX 520 kb)

Additional file 3: Figure S1. Scatterplot matrix and genetic correlation (upper diagonal) between traits. $\mathrm{CY}=$ Cane Yield; $\mathrm{SC}=$ Sugar Content. (JPG 5656 kb)

Additional file 4: Table S4. Dataset of 1745 polymorphic DArT and TRAP markers scored on the 88 sugarcane accessions and used to estimate genetic relationship among clones. Table S5. Dice distances matrix. Table S6. Ultrametric distances matrix. (XLSX 596 kb)

Additional file 5: Figure S2. Quantile-quantile plots for the P-values achieved in the genome-wide association studies (GWAS). (JPG 94 kb)
Additional file 6: Table S7. Significant marker-trait associations found in the GWA study on a sugarcane breeding population considering a false-discovery rate $(F D R, a=0.01)$ to control for multiple testing. Markers associated to more than one trait are in bold. $\mathrm{CY}=$ Cane Yield; $\mathrm{SC}=$ Sugar Content. (DOCX $26 \mathrm{~kb})$

\section{Abbreviations}

ASE, allelic substitution effect; CONICET, Consejo Nacional de Investigaciones Científicas y Técnicas; CY, cane yield; DArT, Diversity Arrays Technology; EEAOC, Estación Experimental Agroindustrial Obispo Colombres; GWAS, genome-wide association; IVT, Infield Variety Trials; LD, linkage disequilibrium; MAF, minor allele frequency; MINCYT, Ministerio de Ciencia, Tecnología e Innovación Productiva; PCA, principal component analysis; QTL, quantitative trait loci; SC, sugar content; SCBP-EEAOC, sugarcane breeding program of Estación Experimental Agroindustrial Obispo Colombres; TRAP, target region amplification polymorphism.

\section{Acknowledgements}

We thank Natalia Ovejero for technician support in TRAP markers development in LICOR system.

\section{Funding}

Ministerio de Ciencia, Tecnología e Innovación Productiva (MINCYT, Argentina) provided funding for Sugarcane DArT markers. Estación Experimental Agroindustrial Obispo Colombres (EEAOC) and Consejo Nacional de Investigaciones Científicas y Técnicas (CONICET) provided the financial support of the studies conducted in this project. MPF and APC are CONICET members; JR is CONICET fellow.

\section{Availability of data and materials}

The datasets supporting the conclusions about phylogenetic data of this article are available in the Dryad Digital Repository [http://dx.doi.org/10.5061/ dryad.mv88m]. Other relevant data are within the paper and its Supporting Information files.

\section{Authors' contributions}

JR carried out the molecular genetic studies, performed the statistical analysis of multi-QTL association mapping, the comparative mapping analysis, participated in the sequence alignment and drafted the manuscript. LG participated in the design of the study, performed the statistical analysis of multi-QTL association mapping. MFP generated molecular data and critically revised the manuscript SO and MIC generated phenotypic data and performed the statistical analysis of these. EMP participated in the sequence alignment. MIC, BW and APC conceived of the study, and participated in its design and coordination. APC revised the manuscript. All authors read and approved the final manuscript.

\section{Competing interests}

The authors declare that they have no competing interests.

Consent for publication

Not applicable.

Ethics approval and consent to participate

Not applicable.

\section{Author details}

${ }^{1}$ Estación Experimental Agroindustrial Obispo Colombres (EEAOC)- Consejo Nacional de Investigaciones Científicas y Técnicas (CONICET), Instituto de Tecnología Agroindustrial del Noroeste Argentino (ITANOA), Av. William Cross 3150, Las Talitas T4101XAC, Tucumán, Argentina. ${ }^{2}$ Departamento de Biometría, Estadística y Cómputos, Facultad de Agronomía, Universidad de la República, Garzón 780, 12900 Montevideo, Uruguay. ${ }^{3}$ Agronomy Department, University of Wisconsin - Madison, 1575 Linden Dr., Madison, WI 53706, USA.

Received: 28 April 2015 Accepted: 14 June 2016

Published online: 24 June 2016

References

1. Heller-Uszynska K, Uszynski G, Huttner E, Evers M, Carlig J, Caig V, Aitken K, Jackson P, Piperidis G, Cox M, Gilmour R, D'Hont A, Butterfield M, Glaszmann 
JC, Kilian A. Diversity Arrays Technology effectively reveals DNA polymorphism in a large and complex genome of sugarcane. Mol Breed. 2011;28:37-55

2. Daniels J, Roach BT. Taxonomy and evolution. In: Heinz DJ, editor. Sugarcane improvement through breeding. Amsterdam: Elsevier Press; 1987. p. 7-84.

3. Silva JA, Bressiani JA. Sucrose synthase molecular marker associated with sugar content in elite sugarcane progeny. Genet Mol Biol. 2005;28:294-8.

4. Remington DL, Thornsberry JM, Matsuoka Y, Wilson LM, Whitt SR, Doebley J, Kresovich S, Goodman MM, Buckler ESIY. Structure of linkage disequilibrium and phenotypic associations in the maize genome. Proc Natl Acad Sci USA. 2001:98(20):11479-84.

5. Kraakman ATW, Niks RE, Van den Berg PMM, Stam P, Van Eeuwijk FA. Linkage disequilibrium mapping of yield and yield stability in modern spring barley cultivars. Genetics. 2004;168:435-46.

6. Breseghello F, Sorrells ME. Association mapping of kernel size and milling quality in wheat (Triticum aestivum L.) cultivars. Genetics. 2006;172:1165-77.

7. Agrama HA, Eizenga GC, Yan W. Association mapping of yield and its components in rice cultivars. Mol Breed. 2007;19:341-56.

8. D'hoop BB, Paulo MJ, Mank RA, van Eck HJ, van Eeuwijk FA. Association mapping of quality traits in potato (Solanum tuberosum L.). Euphytica. 2008; 161:47-60.

9. Stich B, Melchinger AE, Heckenberger M, Möhring J, Schechert A, Piepho HP. Association mapping in multiple segregating populations of sugar beet (Beta vulgaris L.). Theor Appl Genet. 2008;117:1167-79.

10. Flint-Garcia S, Thornsberry JM, Buckler ES. Structure of linkage disequilibrium in plants. Annu Rev Plant Biol. 2003;54:357-74.

11. Rafalski A. Applications of single nucleotide polymorphisms in crop genetics. Curr Opin Plant Biol. 2002;5:94-100.

12. Jannoo N, Grivet L, Dookun A, D'Hont A, Glaszmann JC. Linkage disequilibrium among modern sugarcane cultivars. Theor Appl Genet. 1999; 99:1053-60.

13. Raboin LM, Pauquet J, Butterfield M, D'Hont A, Glaszmann JC. Analysis of genome-wide linkage disequilibrium in the highly polyploid sugarcane. Theor Appl Genet. 2008:116:701-14.

14. Newman DL, Abney M, McPeek MS, Ober C, Cox NJ. The importance of genealogy in determining genetic associations with complex traits. Am J Hum Genet. 2001;69:1146-8.

15. Helgason A, Yngvadttir B, Hrafnkelsson B, Gulcher J, Stefnsson K. An Icelandic example of the impact of population structure on association studies. Nat Genet. 2005;37:90-5.

16. Pritchard JK, Stephens M, Rosenberg NA, Donnelly P. Association mapping in structured populations. Am J Hum Genet. 2000;67:170-81.

17. Yu J, Pressoir G, Briggs WH, Vroh Bi I, Yamasaki M, Doebley JF, McMullen MD, Gaut BS, Nielsen DM, Holland JB, Kresovich S, Buckler ES. A unified mixed-model method for association mapping that accounts for multiple levels of relatedness. Nat Genet. 2006;38:203-8.

18. Parisseaux $B$, Bernado R. In silico mapping of quantitative trait loci in maize. Theor Appl Genet. 2004;109:508-14.

19. Malosetti M, van der Linden CG, Vosman B, van Eeuwijk F. A mixed-model approach to association mapping using pedigree information with an illustration of resistance to Phytophthora infestans in potato. Genetics. 2007;175:879-89.

20. Kilian A, Huttner E, Wenzl P, Jaccoud D, Carling J, Caig V, Evers M, HellerUszynska K, Cayla C, Patarapuwadol S, Xia L, Yang S, Thomson B: The fast and the cheap: SNP and DArT-based whole genome profiling for crop improvement. In Proceedings of the international congress in the wake of the double helix: from the green revolution to the gene revolution: 27-31 May 2003; Bologna, Italy; 2005:443-461.

21. Alwala S, Suman A, Arro JA, Veremis JC, Kimbeng CA. Target region amplification polymorphism (TRAP) for assessing genetic diversity in sugarcane germplasm collections. Crop Sci. 2006;46:448-55.

22. Creste S, Accoroni KA, Pinto LR, Vencovsky R, Gimenes MA, Xavier MA Landell MG. Genetic variability among sugarcane genotypes based on polymorphisms in sucrose metabolism and drought tolerance genes. Euphytica. 2010;172:435-46.

23. Paterson AH, Bowers JE, Bruggmann R, Dubchak I, Grimwood J, Gundlach $H_{\text {, }}$ Haberer G, Hellsten U, Mitros T, Poliakov A, Schmutz J, Spannagl M, Tang H, Wang X, Wicker T, Bharti AK, Chapman J, Feltus FA, Gowik U, Grigoriev IV, Lyons E, Maher CA, Martis M, Narechania A, Otillar RP, Penning BW, Salamov AA, Wang Y, Zhang L, Carpita NC, et al. The Sorghum bicolor genome and the diversification of grasses. Nature. 2009;457:551-6.
24. Jannoo N, Grivet L, Chantret N, Garsmeur O, Glaszmann JC, Arruda P, D'Hont A. Orthologous comparison in a gene-rich region among grasses reveals stability in the sugarcane polyploid genome. Plant J. 2007;50(4):574-85.

25. Wang ML, Zhu C, Barkley NA, Chen Z, Erpelding JE, Murray SC, Tuinstra MR, Tesso T, Pederson GA, Yu J. Genetic diversity and population structure analysis of accessions in the US historic sweet sorghum collection. Theor Appl Genet. 2009;120:13-23.

26. Price AL, Patterson NJ, Plenge RM, Weinblatt ME, Shadick NA, Reich D. Principal components analysis corrects for stratification in genome-wide association studies. Nat Genet. 2006;38:904-9.

27. Gouy M, Rousselle Y, Thong Chane A, Anglade A, Royaert S, Nibouche S, Costet L. Genome wide association mapping of agro-morphological and disease resistance traits in sugarcane. Euphytica. 2014;202:269-84.

28. Wei X, Jackson P, Hermann S, Kilian A, Heller-Uszynska K, Deomano E. Simultaneously accounting for population structure, genotype by environment interaction, and spatial variation in marker-trait associations in sugarcane. Genome. 2010;53:973-81.

29. Ostengo S, Espinosa MA, Díaz JV, Chavanne ER, Costilla DD, Cuenya MI. Distribución de variedades comerciales de caña de azúcar en la provincia de Tucumán, R. Argentina. Relevamiento de la campaña 2013/2014. Revista Avance Agroindustrial. 2014;35(4):1.

30. Legendre BL, Henderson MT. The history and development of sugar yield calculations. J Am Soc Sugarcane Technol. 1972;2:10-8.

31. Fogliata FA. Composición química y vegetativa. In: Felipe LE, editor. Agronomía de la caña de azúcar. Argentina: El Graduado; 1995. p. 163-209.

32. Cuenya MI, Ostengo S, García MB, Chavanne ER, Ahmed M, Díaz Romero C, Costilla DD, Espinosa MA. Comportamiento productivo y fitosanitario de TUC 97-8, una nueva variedad de caña de azúcar (Saccharum spp.) para Tucumán, R. Argentina. Rev ind agríc Tucumán. 2013;90(1):01-8.

33. Romero ER, Scandaliaris J, Olea I, Tonatto J, Sotomayor L: Comparative emergence and earlier growth of plant and ratoon cane, variety TUC CP 77-42, under different field temperature regimes. In Proceeding XXV International Society of Sugar Cane Technologists Congress: 1-4 January 2005; Guatemala; 2:168-75.

34. Pasam RK, Sharma R, Malosetti M, van Eeuwijk FA, Haseneyer G, Kilian B, Graner A. Genome-wide association studies for agronomical traits in a worldwide spring barley collection. BMC Plant Biol. 2012;12:16.

35. Matthies IE, Malosetti M, Röder MS, van Eeuwijk F. Genome-wide association mapping for kernel and malting quality traits using historical European barley records. PLoS One. 2014;9:e110046.

36. Gutiérrez L, Germán S, Pereyra S, Hayes PM, Pérez CA, Capettini F, Locatelli A, Berberian NM, Falconi EE, Estrada R, Fros D, Gonza V, Altamirano H, Huerta-Espino J, Neyra E, Orjeda G, Sandoval-Islas S, Singh R, Turkington K, Castro AJ. Multienvironment multi-QTL association mapping identifies disease resistance QTL in barley germplasm from Latin America. Theor Appl Genet. 2015;128:501-16.

37. Kollers S, Rodemann B, Ling J, Korzun V, Ebmeyer E, Argillier O, Hinze M, Plieske J, Kulosa D, Ganal MW, Röder MS. Whole genome association mapping of Fusarium head blight resistance in European winter wheat (Triticum aestivum L.). PLoS One. 2013;8(2):e57500.

38. Tondelli A, Xu X, Moragues M, Sharma R, Schnaithmann F, Ingvardsen C, Manninen O, Comadran J, Russell J, Waugh R, Schulman AH. Structural and temporal variation in genetic diversity of European spring two-row barley cultivars and association mapping of quantitative traits. Plant Genome. 2013;6(2):1.

39. The R Foundation for statistical Computing. http://www.r-project.org/. Accessed 16 June 2016

40. Holland J, Nyquist W, Cervantes C: Estimating and Interpreting Heritability for Plant Breeding: An Update. In Plant Breeding Reviews. Edited by Janick J, Wiley J \& Sons p. 2003: 9-112.

41. Plant DNA Extraction Protocol for DArT. http://www.diversityarrays.com/ sites/default/files/pub/DArT_DNA_isolation.pdf. Accessed 16 June 2016.

42. Nei M, Li W. Mathematical model for studying genetic variation in terms of restriction endonucleases. Proc Nat Acad Sci USA. 1979;76:427-34

43. Perrier X, Flori A, Bonnot F. Methods of data analysis. In: Hamon PS, Seguin M, Perrier X, Glaszmann JC, editors. Genetic diversity of cultivated tropical plants. Montpellier: Cirad; 2003. p. 31-63.

44. Bernardo R. Genome wide markers as cofactors for precision mapping of quantitative trait loci. Theor Appl Genet. 2013;126:999-1009.

45. Aitken KS, McNeil MD, Hermann S, Bundock PC, Kilian A, Heller-Usznska K, Henry RJ, Li J. A comprehensive genetic map of sugarcane that provides 
enhanced map coverage and integrates high-throughput Diversity Array Technology (DArT) markers. BMC Genomics. 2014;15:152-63.

46. Patterson N, Price AL, Reich D. Population structure and eigenanalysis. PLoS Genet. 2006;2:e190.

47. Wu C, DeWan A, Hoh J, Wang Z. A comparison of association methods correcting for population stratification in case-control studies. Ann Hum Genet. 2011;75:418-2.

48. Gutierrez L, Berberian N, Capettini F, Falcioni E, Fros D, Germán S, Hayes PM, Huerta-Espino J, Herrera S, Pereyra S, Pérez C, Sandoval-Islas S, Singh R, Castro AJ. Genome-Wide Association Mapping Identifies Disease-Resistance QTLs in Barley Germplasm From Latin America. In: Advance In Barley Breeding. Netherlands: Springer; 2013. p. 209-16.

49. Kang HM, Zaitlen NA, Wade CM, Kirby A, Heckerman D, Daly MJ, Eskin E. Efficient control of population structure in model organism association mapping. Genetics. 2008;178:1709-23.

50. Lipka AE, Tian F, Wang Q, Peiffer J, Li M, Bradbury PJ, Gore MA, Buckler ES, Zhang Z. GAPIT: genome association and prediction integrated tool. Bioinformatics. 2012;28:2397-9.

51. Brandariz S, Quero G, Fernandez S, Gutierrez L: mmQTL R package. Cran repository 2015.

52. Boer M, Wright D, Feng L, Podlich D, Luo L, Cooper M, Van Eeuwijk F. A mixed model QTL analysis for multiple environment trial data using environmental covariables for QTLxE with an example in maize. Genetics. 2007;177:1801-13.

53. Stich B, Piepho HP, Schulz B, Melchinger AE. Multi-trait association mapping in sugar beet (Beta vulgaris L.). Theor Appl Genet. 2008;117:947-54.

54. Mathews KL, Malosetti M, Chapman S, Mclntyre L, Reynolds M, Shorter R, van Eeuwijk FA. Multi-environment QTL mixed models for drought stress adaptation in wheat. Theor Appl Genet. 2008;117:1077-91.

55. Schweder T, Spjotvoll E. Plots of p-values to evaluate many tests simultaneously. Biometrika. 1982;69(3):493-502.

56. Balding DJ. A tutorial on statistical methods for population association studies. Nat Rev Genet. 2006;7:781-91.

57. Altschul SF, Gish W, Miller W, Myers EW, Lipman DJ. Basic local alignment search tool. J Mol Biol. 1990:215:403-10.

58. Breseghello F, Sorrells ME. Association analysis as a strategy for improvement of quantitative traits in plants. Crop Sci. 2006:46:1323-30.

59. Sorkheh K, Malysheva-otto LV, Wirthensohn MG, Tarkesh-esfahani S, Martínez-gómez P. Linkage disequilibrium, genetic association mapping and gene localization in crop plants. Genet Mol Biol. 2008;31:805-14.

60. Zhu C, Gore M, Buckler ES, Yu J. Status and Prospects of Association Mapping in Plants. Plant Genome J. 2008;1:5.

61. Rebai A, Goffinet B. Power of tests for QTL detection using replicated progenies derived from a diallel cross. Theor Appl Genet. 1993;86:1014-22.

62. Melchinger AE, Utz HF, Schön CC. Quantitative trait locus (QTL) mapping using different testers and independent population samples in maize reveals low power of QTL detection and large bias in estimates of QTL effects. Genetics. 1998;149:383-403.

63. Lande R, Thompson R. Efficiency of marker-assisted selection in the improvement of quantitative traits. Genetics. 1990;124:743-56.

64. Bernardo R. What proportion of declared QTL in plants are false? Theor Appl Genet. 2004;109:419-24.

65. Wong CK, Bernardo R. Genome wide selection in oil palm: Increasing selection gain per unit time and cost with small populations. Theor Appl Genet. 2008;116(6):815-24

66. Andersen JR, Schrag T, Melchinger AE, Zein I, Lubberstedt T. Validation of Dwarf8 polymorphisms associated with flowering time in elite European inbred lines of maize (Zea mays L.). Theor Appl Genet. 2005;111:206-17.

67. Skot L, Humphreys MO, Armstead I, Heywood S, Skot KP, Sanderson R, Thomas ID, Chorlton KH, Hamilton NRS. An association mapping approach to identify flowering time genes in natural populations of Lolium perenne ( $\mathrm{L}$. ). Mol Breed. 2005;15:233-45.

68. Skot L, Humphreys J, Humphreys MO, Thorogood D, Gallagher J, Sanderson $R$, Armstead IP, Thomas ID. Association of candidate genes with flowering time and water soluble carbohydrate content in Lolium perenne (L.). Genetics. 2007; 177:535-47.

69. Ehrenreich IM, Stafford PA, Purugganan MD. The genetic architecture of shoot branching in Arabidopsis thaliana: a comparative assessment of candidate gene associations vs. quantitative trait locus mapping. Genetics. 2007;176:1223-36
70. Salvi S. Conserved non-coding genomic sequences associated with a flowering-time quantitative trait locus in maize. Proc Natl Acad Sci U S A. 2007;104:11376-81.

71. Debibakas S, Rocher S, Garsmeur O, Toubi L, Roques D, D'Hont A, Hoarau J$Y$, Daugrois $\mathrm{JH}$. Prospecting sugarcane resistance to Sugarcane yellow leaf virus by genome-wide association. Theor Appl Genet. 2014;127:1719-32.

72. Huang E, Aitken KS, George A. Association studies. In: Henry R, Kole C, editors. Genetics, genomics and breeding of sugarcane. USA: Science Publishers, Enfield; 2010. p. 43-68.

73. Wei $\mathrm{X}$, Jackson PA, McIntyre CL, Aitken KS, Croft B. Associations between DNA markers and resistance to diseases in sugarcane and effects of population substructure. Theor Appl Genet. 2006;114:155-64.

74. Pan YB, Burner DM, Legendre BL, Grisham MP, White WH. An assessment of the genetic diversity within a collection of Saccharum spontaneum L. with RAPD-PCR. Genet Resour Crop Evol. 2005:51:895-903.

75. Arro JA: Genetic diversity among sugarcane clones using Target Region Amplification Polymorphism (TRAP) markers and pedigree relationships. PhD thesis. University of the Philippines, Agronomy and Environmental Management Department, Philippines; 2005.

76. Perera MF, Arias ME, Costilla D, Luque AC, García MB, Romero CD, Racedo J, Ostengo S, Filippone MP, Cuenya MI, Castagnaro AP. Genetic diversity assessment and genotype identification in sugarcane based on DNA markers and morphological traits. Euphytica. 2012;185:491-510.

77. Mclntyre CL, Casu RE, Drenth J, Knight D, Whan VA, Croft BJ, Jordan DR, Manners JM. Resistance gene analogues in sugarcane and sorghum and their association with quantitative trait loci for rust resistance. Genome. 2005;48:391-400.

78. Butterfield MK: Marker assisted breeding in sugarcane: a complex polyploid. PhD Thesis. University of Stellenbosch, Stellenbosch, South Africa; 2007.

79. Mace ES, Jordan DR. Integrating sorghum whole genome sequence information with a compendium of sorghum QTL studies reveals uneven distribution of QTL and of gene-rich regions with significant implications for crop improvement. Theor Appl Genet. 2011;123:169-91.

80. Shiringani AL, Frisch M, Friedt W. Genetic mapping of QTLs for sugar-related traits in a RIL population of Sorghum bicolor L. Moench Theor Appl Genet. 2010;121:323-36.

81. Ritter KB, Jordan DR, Chapman SC, Godwin ID, Mace ES, Mclntyre CL. Identification of QTL for sugar-related traits in a sweet $x$ grain sorghum (Sorghum bicolor L. Moench) recombinant inbred population. Mol Breed. 2008;22:367-84

82. Murray SC, Sharma A, Rooney WL, Klein PE, Mullet JE, Mitchell SE, Kresovich S. Genetic improvement of sorghum as a biofuel feedstock: I. QTL for stem sugar and grain nonstructural carbohydrates. Crop Sci. 2008;48:2165-79.

83. Garsmeur O, Charron C, Bocs S, Jouffe V, Samain S, Couloux A, Droc G, Zini C, Glaszmann J-C, Van Sluys M-A, D'Hont A. High homologous gene conservation despite extreme autopolyploid redundancy in sugarcane. New Phytol. 2011;189:629-42.

84. Garcia AAF, Mollinari M, Marconi TG, Serang OR, Silva RR, Vieira MLC, Vicentini R, Costa EA, Mancini MC, Garcia MOS, Pastina MM, Gazaffi R, Martins ERF, Dahmer N, Sforça DA, Silva CBC, Bundock P, Henry RJ, Souza GM, van Sluys M-A, Landell MGA, Carneiro MS, Vincentz MAG, Pinto LR, Vencovsky $R$, Souza AP. SNP genotyping allows an in-depth characterisation of the genome of sugarcane and other complex autopolyploids. Sci Rep. 2013;3:3399.

85. Beavis WD, QTL analysis. Power, precision, and accuracy. In: Paterson AH, editor. Molecular dissection of complex traits. New York: CRC Press; 1998. p. 145-62. 